This item was submitted to Loughborough's Research Repository by the author.

Items in Figshare are protected by copyright, with all rights reserved, unless otherwise indicated.

\title{
Are BRICS exchange rates chaotic?
}

\section{PLEASE CITE THE PUBLISHED VERSION}

https://doi.org/10.1080/13504851.2018.1537473

\section{PUBLISHER}

(C) Taylor \& Francis

\section{VERSION}

AM (Accepted Manuscript)

\section{PUBLISHER STATEMENT}

This is an Accepted Manuscript of an article published by Taylor \& Francis in Applied Economics Letters on 24 October 2018, available online: http://www.tandfonline.com/10.1080/13504851.2018.1537473.

\section{LICENCE}

CC BY-NC-ND 4.0

\section{REPOSITORY RECORD}

Plakandaras, Vasilios, Rangan Gupta, Luis A. Gil-Alana, and Mark Wohar. 2018. "Are BRICS Exchange Rates Chaotic?". figshare. https://hdl.handle.net/2134/36366. 


\title{
Are BRICS Exchange Rates Chaotic?
}

\author{
Vasilios Plakandaras ${ }^{1+}$, Rangan Gupta ${ }^{2}$, Luis A. Gil-Alana ${ }^{3}$ and Mark E. \\ Wohar $^{4}$ \\ ${ }^{1}$ Department of Economics, Democritus University of Thrace, Komotini, Greece, email: \\ vplakand@econ.duth.gr \\ ${ }^{2}$ Department of Economics, University of Pretoria, Pretoria, South Africa, email: \\ rangan.gupta@up.ac.za \\ ${ }_{3}^{3}$ Department of Economics, University of Navarra, Spain, email: alana@unav.es \\ ${ }^{4}$ College of Business Administration, University of Nebraska at Omaha USA, and School \\ of Business and Economics, Loughborough University, UK. Email: \\ mwohar@unomaha.edu
}

\section{Abstract}

In this paper, we focus on the stochastic (chaotic) attributes of the US dollar-based exchange rates for Brazil, Russia, India, China and South Africa (BRICS) using a longrun monthly dataset covering 1812M01-2017M12, 1814M01-2017M12, 1822M072017M12, 1948M08-2017M12, and 1844M01-2017M12, respectively. For our purpose, we consider the Lyapunov exponents, robust to nonlinear and stochastic systems, in both full - samples and in rolling windows. For comparative purposes, we also evaluate a longrun dataset of a developed currency market, namely British pound over the period of 1791M01-2017M12. Our empirical findings detect chaotic behavior only episodically for all countries before the dissolution of the Bretton Woods system, with the exception of the Russian ruble. Overall, our findings suggest that the establishment of the free floating exchange rate system have altered the path of exchange rates removing chaotic dynamics from the phenomenon, and hence, the need for policymakers to intervene in the currency markets for the most important emerging market bloc, should be carefully examined.

\section{JEL codes: C46, E52.}

Keywords: Exchange rate, chaos, Lyapunov exponent.

Declarations of interest: none.

\footnotetext{
${ }^{+}$Corresponding author, University Campus, Komotini, 69100, Greece. Tel:+306944503768. We would like to thank the editor Prof. David A. Peel and an anonymous referee for many helpful comments. Any remaining errors are solely our own.
} 


\section{Are BRICS Exchange Rates Chaotic?}

\section{Introduction}

Exchange rate movements are known to potentially influence many financial and economic variables such as interest rates, trade, output, and equity prices. The extant literature dealing with exchange rate predictability is huge, to say the least (see, Balcilar et al., (2016) and Christou et al., (forthcoming) for detailed reviews). In this regard, determining whether exchange rate behavior is characterized by chaos is of paramount importance. Theoretically, a chaotic system is a random-looking nonlinear deterministic process with irregular periodicity and sensitivity to initial conditions, whose complexity makes it difficult to predict.

The objective of this paper is to use the Lyapunov exponent to analyze whether the U.S. dollar-based exchange rates for Brazil, Russia, India, China and South Africa (i.e., the BRICS) and the British pound (for comparison) depict chaotic behavior using the longest possible available monthly data. The decision to look at the BRICS is motivated by their emergence as a powerful economic force. In 2010, about 25 percent of global output emanated from the BRICS (Government of India, 2012). Also, the contribution to global output from the bloc is expected to surpass that of the current world economic powers like G7 countries by 2050 (Wilson and Purushothaman, 2003). Naturally, unpredictable exchange rate movements are likely to affect the growth potential of BRICS, and with them that of the world economy.

The literature on chaos in financial markets in general, is huge (see, Tiwari and Gupta (forthcoming) and Gensel and Unal (2016) for a review), and this also includes the currency markets (see for example, Serletis and Gogas (1997), Cristescu et al., (2009), BenSaïda and Litimi (2013), Lahmiri (2017)). While earlier studies have concentrated primarily on

developed markets, Kumar and Kamaiah (2016), and Bhattacharya et al., (2018) have recently detected chaotic dynamics in the exchange rates of BRICKS. While, the former 
study finds underlying chaotic structure for all five markets, the latter shows that the same does not hold for South Africa. Given this, our objective is to provide a definitive answer as to the existence or non-existence of chaotic dynamics in the BRICS exchange rates using the longest spans of data available, and hence, taking out the possibility of the results being sample-specific. We build on this argument further, by carrying out a time-varying (rolling window) analysis of chaos. While, a full-sample analysis is informative, the final results on chaos could be driven by the selective existence of chaos only on a large sub-sample or sub-samples but not universally.

\section{Methodology: Lyapunov Exponent}

The basic idea behind the detection of chaos lies with the dependence of chaotic processes to initial conditions. The Lyapunov exponent $\lambda$ measures the divergence between paths generated in time according to the different initial conditions. In order to identify a system as chaotic, the corresponding Lyapunov exponent should be strictly positive. In this paper, we follow the procedure described in BenSaïda and Litimi (2013) in order to estimate the maximum Lyapunov exponent. In mathematical notation:

$$
x_{t}=f\left(x_{t-L}+x_{t-2 L}+\cdots+x_{t-m L}\right)+\varepsilon_{t},
$$

where $L$ is the time delay, $f$ is an unknown chaotic map, $m$ is the embedding dimension of the system and $\varepsilon_{\mathrm{t}}$ represents the added noise. Briefly, the exponent is given by:

$$
\hat{\lambda}=\frac{1}{2 M} \ln v_{i}
$$

where $M$ is an arbitrary selected number of observations often approximating the $2 / 3$ of the total span and $v_{i}$ is the largest eigenvalue of the matrix $\left(T_{M} U_{o}\right)\left(T_{M} U_{o}\right)^{\prime}$, with

$$
\begin{aligned}
& U_{0}=\left(\begin{array}{lllll}
1 & 0 & 0 & \ldots & 0
\end{array}\right)^{\prime} \\
& T_{M}=\prod_{t=1}^{M-1} J_{M-t}
\end{aligned}
$$

In the case of scalar time series the chaotic map $f$ generating the series is usually unknown. BenSaïda and Litimi (2013) approximate the chaotic map based on a neural network with one hidden layer of neurons and one output layer. In mathematical notation:

$$
x_{t} \approx a_{0}+\sum_{j=1}^{q} a_{j} \tanh \left(\beta_{0, j}+\sum_{i=1}^{m} \beta_{i, j} x_{t-i L}\right)+\varepsilon_{t},
$$


with $q$ declares the hidden layers of the neural network with a tangent activation function. The order of $(L, m, q)$ defines the complexity of the system and is selected according to the triplet that provides the maximum value of the exponent $\lambda$.

Assuming the existence of chaos as the null hypothesis, we can reject it in favor of the nonexistence of chaos based on a one-sided statistical test. ${ }^{1}$ In this way, a system is identified as chaotic when both assumptions are met: a) we find a positive Lyapunov exponent and b) we are unable to reject the null hypothesis on the existence of chaos.

\section{Empirical results}

We compile a dataset of nominal exchange rates for BRICS and the U.K. expressed as local currency to U.S. dollar compiled from the Global Financial Database, and take log-returns. We begin our analysis examining both the entire sample and rolling windows of $40 \%, 50 \%$ and $60 \%$ of the total length with a sliding window of one. With this smooth transition in time we uncover time patterns that may exist during distinct periods, but are typically hidden during the examination of the entire sample.

We now proceed to examining the chaotic behaviour of all exchange rates using the Lyapunov exponent (Table 1). Given that we are interested in both the sign and the statistical significance of our results, we report the percentage of instances that the exponent is positive in all windows. In those instances that the exponent is positive, we also test the statistical significance of the exponent in order to infer upon the rejection of the null hypothesis on the existence of chaos.

[Table 1]

As we observe from Table 1, we detect chaos only episodically and for a limited number of cases. More specifically, only Russia and China exhibit chaotic behaviour on the entire sample, while the detection rate in rolling windows is high only for Russia ${ }^{2}$. In all other cases the detection of chaos varies from $3 \%-30 \%$ of windows. In order to observe this, we plot the estimated Lyapunov exponent for all countries and windows in Figure 1.

\footnotetext{
${ }^{1}$ For more information on the derivation of the test, the interested reader is referred to BenSaïda and Litimi (2013).

${ }^{2}$ In the case of Russia the estimation of the largest window was not possible, since we could not estimate the eigenvalue of the matrix.
} 
[Figure 1]

The Lyapunov exponent for Brazil is positive for the smallest window in the post-Bretton Woods period but only for a limited number of months. More specifically, positive values are observed during the 1990s, a period of high inflationary pressures for Brazil and in the past 1994 period where the Brazilian real is pegged to the U.S. dollar. In contrast, the Russian ruble exhibits consistent chaotic behavior in the entire post WWII period. Both the Chinese yuan and the Indian rupee have a negative exponent in the entire sample and for all windows, so the hypothesis of chaos is strongly rejected. An interesting pattern unveils for the South African rand. The exponent is below zero until the end of WWII and the beginning of the Bretton Woods period. During the Bretton Woods period, the rand exhibits low chaotic behaviour in a number of instances up to 1971, with a large positive exponent after the dissolution of the fixed exchange rates system. In the floating exchange rate era, the exponent turns negative almost for every window.

In contrast, from the beginning of the $19^{\text {th }}$ century up to WWII the exponent for the English pound is positive, where there is an abrupt change in the positive trend and the coefficient turns negative for the entire Bretton Woods period. The coefficient turns positive again around 0.5 at the dissolution of the fixed exchange rates system, reverts to positive up to the turbulent period of the 1980s for the British economy and then moves back negative.

Overall, our examination of chaotic behaviour of the exchange rates of the BRICS reveals weak evidence of chaos and only for the period before Bretton Woods, while in the modern floating exchange rates era only the Russian ruble retains chaotic dynamics, something strongly observable during the period of transition from the Soviet Union to the Russian Federation. $^{3}$

\section{Concluding Remarks}

In this paper, we focus on the statistical characteristics of exchange rates series for the BRICS and the U.K. in terms of their chaotic behavior using Lyapunov exponents in both

\footnotetext{
${ }^{3}$ The descriptive statistics and data plots are reported on the Appendix. Following the suggestion of an anonymous reviewer we also report the results from alternative chaos detection tests. The empirical finding of the BDS test also corroborate to the ones from the our Lyapunov exponent, while the correlation dimension are inconclusive.
} 
full-sample and rolling windows. In doing so, we compile a long-run dataset covering over two centuries of monthly data in three cases (Brazil, Russia, and the UK), nearly two centuries for India and South Africa, and seventy years for China. Our empirical findings show that chaos is observed only for the Russian rumble and episodically for the other series, unlike suggested in earlier studies on the BRICS. Overall, our findings point that the establishment of the free floating exchange rate system has resulted in a significant change in the underlying data generating mechanism of the exchange rates of the BRICS, to the extent that chaotic dynamics cease to exist. Thus, the absolute necessity suggested in earlier studies for policymakers to intervene in the currency markets for the most important emerging market bloc, barring Russia, and in the developed economy of the UK to reduce volatility (uncertainty), is not necessarily warranted. 


\section{References}

Balcilar, M., Gupta, R., Kyei, C., and Wohar, M.E. (2016). Does Economic Policy Uncertainty Predict Exchange Rate Returns and Volatility? Evidence from a Nonparametric Causality-in-Quantiles Test. Open Economies Review, 27(2), 229250 .

BenSaïda A., and Litimi H. (2013). High level chaos in the exchange and index markets, Chaos, Solitons and Fractals, 54, 90-95.

Bhattacharya, S.N., Bhattacharya, M., and Roychoudhury, B. (2018). Behaviour of the Foreign Exchange Rates of BRICS: Is it Chaotic? The Journal of Prediction Markets, 11(2), 1-19.

Christou, C., Gupta, R., Hassapis, C., and Suleman, T. (Forthcoming). The Role of Economic Uncertainty in Forecasting Exchange Rate Returns and Realized Volatility: Evidence from Quantile Predictive Regressions. Journal of Forecasting.

Cristescu, C.P., Stan, C., and Scarlat, E.I. (2009). The dynamics of exchange rate time series and the chaos game. Physica A, 388, 4845-4855.

Gensel M. and Unal G. (2016) Testing Non-Linear Dynamics, Long Memory and Chaotic Behaviour of Energy Commodities. MPRA Paper No. 74115.

Government of India (2012) The BRICS Report (New Delhi 2012). Oxford University Press, Oxford. http://www.g20civil.com/documents/brics/brics-report.pdf.

Kumar, A.S., and Kamaiah, B. (2016). Efficiency, non-linearity and chaos: evidences from BRICS foreign exchange markets. Theoretical and Applied Economics, XXIII(1), 103-118.

Lahmiri, S. (2017). Investigating existence of chaos in short and long term dynamics of Moroccan exchange rates. Physica A, 465, 655-661.

Serletis A., and Gogas P. (1997). Chaos in East European black market exchange rates, Research in Economics, 51(4), 359-385.

Tiwari, A. K., and Gupta, R. (Forthcoming). Chaos in G7 Stock Markets using Over One Century of Data: A Note. Research in International Business and Finance.

Wilson D., and Purushothaman, R. (2003) Dreaming With BRICs: The Path to 2050. Goldman Sachs Global Economics, Paper No. 99. 


\begin{tabular}{|c|c|c|c|c|c|c|c|c|c|c|c|}
\hline \multicolumn{12}{|c|}{ Table 1: Lyapunov exponents } \\
\hline & \multicolumn{2}{|c|}{ Entire sample } & \multicolumn{3}{|c|}{$40 \%$ sample } & \multicolumn{3}{|c|}{$50 \%$ sample } & \multicolumn{3}{|c|}{$60 \%$ sample } \\
\hline Country & $\lambda$ & Obs & $\begin{array}{l}\text { Percentage } \\
\text { of positive } \\
\lambda \text { in the } \\
\text { window }\end{array}$ & $\begin{array}{c}\text { Rejections of } \\
\text { chaos where } \lambda \\
\text { is positive }\end{array}$ & $\begin{array}{c}\text { Window } \\
\text { Obs }\end{array}$ & $\begin{array}{l}\text { Percentage } \\
\text { of positive } \\
\lambda \text { in the } \\
\text { window }\end{array}$ & $\begin{array}{l}\text { Rejections of } \\
\text { chaos where } \\
\lambda \text { is positive }\end{array}$ & $\begin{array}{c}\text { Window } \\
\text { Obs }\end{array}$ & $\begin{array}{c}\text { Percentage } \\
\text { of positive } \lambda \\
\text { in the } \\
\text { window }\end{array}$ & $\begin{array}{l}\text { Rejections } \\
\text { of chaos } \\
\text { where } \lambda \text { is } \\
\text { positive }\end{array}$ & $\begin{array}{c}\text { Window } \\
\text { Obs }\end{array}$ \\
\hline Brazil & $-0.07 *$ & 2479 & 1.95 & 0 & 992 & 2.75 & 0 & 1240 & 3.52 & 0 & 1487 \\
\hline Russia & 0.03 & 2447 & 79.65 & 0 & 979 & 100 & 0 & 1224 & 0 & -- & 1468 \\
\hline India & $-0.32 *$ & 2345 & 0.35 & 0 & 938 & 0.17 & 0 & 1173 & 0 & -- & 1407 \\
\hline China & 0.13 & 832 & 27.49 & 0 & 333 & 0 & -- & 416 & 0 & -- & 499 \\
\hline South Africa & $-0.15^{*}$ & 2087 & 12.93 & 0 & 835 & 3.64 & 0 & 1044 & 0 & -- & 1252 \\
\hline UK & $-0.38^{*}$ & 2723 & 23.67 & 0 & 1089 & 24.89 & 0 & 1362 & 21.19 & 0 & 1634 \\
\hline
\end{tabular}

Note: * denotes rejection of the null hypothesis about the existence of chaos at the $5 \%$ level of statistical significance. The estimation of the eigenvalue for the largest window in Russia was not possible. 


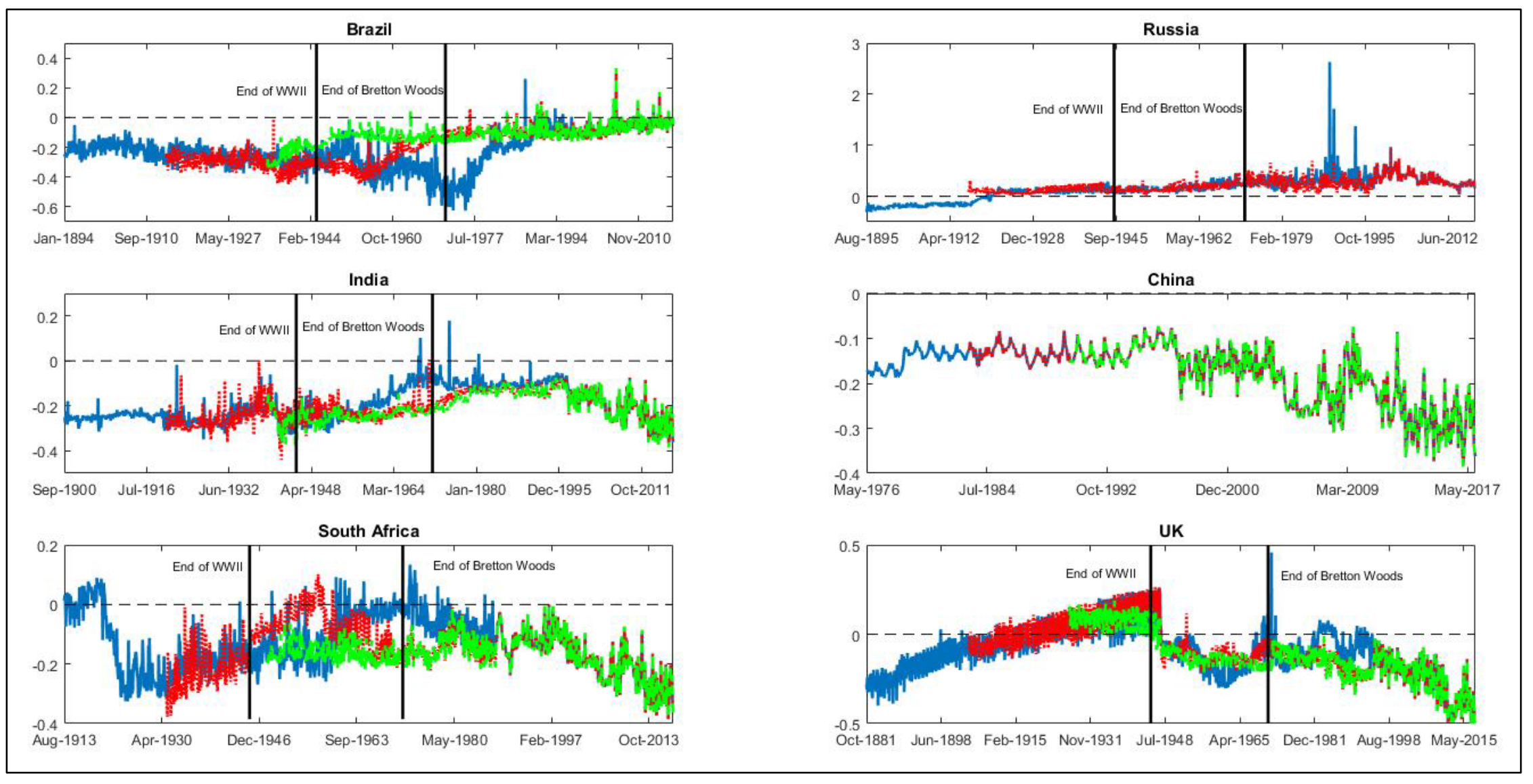

Figure 1: Lyapunov exponents for all exchange rates. The continuous (blue) line depicts the small (40\%) rolling window results, the dotted (red) line depicts the mid (50\%) window length and the dashed (green) line depicts the large (60\%) window length. The estimation of eigenvalues for the largest window in Russia was not possible. 
Appendix

Table A1: Descriptive Statistics

\begin{tabular}{|c|c|c|c|c|c|c|}
\hline Country & Time Span & Mean & SD & Kurtosis & Skewness & $\begin{array}{c}\text { Jarque-Bera test } \\
(p \text {-value })\end{array}$ \\
\hline Brazil & $\begin{array}{c}1812 \mathrm{M} 01- \\
2017 \mathrm{M} 12\end{array}$ & 1.51 & 6.44 & 25.98 & 3.42 & 0.00 \\
\hline Russia & $\begin{array}{c}1814 \mathrm{M} 01- \\
2017 \mathrm{M} 12\end{array}$ & 1.05 & 11.30 & 257.94 & 11.60 & 0.00 \\
\hline India & $\begin{array}{c}1822 \mathrm{M} 07- \\
2017 \mathrm{M} 12\end{array}$ & 0.15 & 3.15 & 255.25 & 10.04 & 0.00 \\
\hline China & $\begin{array}{c}1948 \mathrm{M} 08- \\
2017 \mathrm{M} 12\end{array}$ & 0.78 & 6.51 & 161.81 & 11.50 & 0.00 \\
\hline $\begin{array}{c}\text { South } \\
\text { Africa }\end{array}$ & $\begin{array}{c}1844 \mathrm{M} 01- \\
2017 \mathrm{M} 12\end{array}$ & 0.17 & 2.71 & 42.54 & 1.99 & 0.00 \\
\hline UK & $\begin{array}{l}1791 \mathrm{M} 01- \\
2017 \mathrm{M} 12\end{array}$ & -0.05 & 2.58 & 234.88 & -0.42 & 0.00 \\
\hline
\end{tabular}

Note: SD stands for standard deviation. 
Figure A1. Data Plots

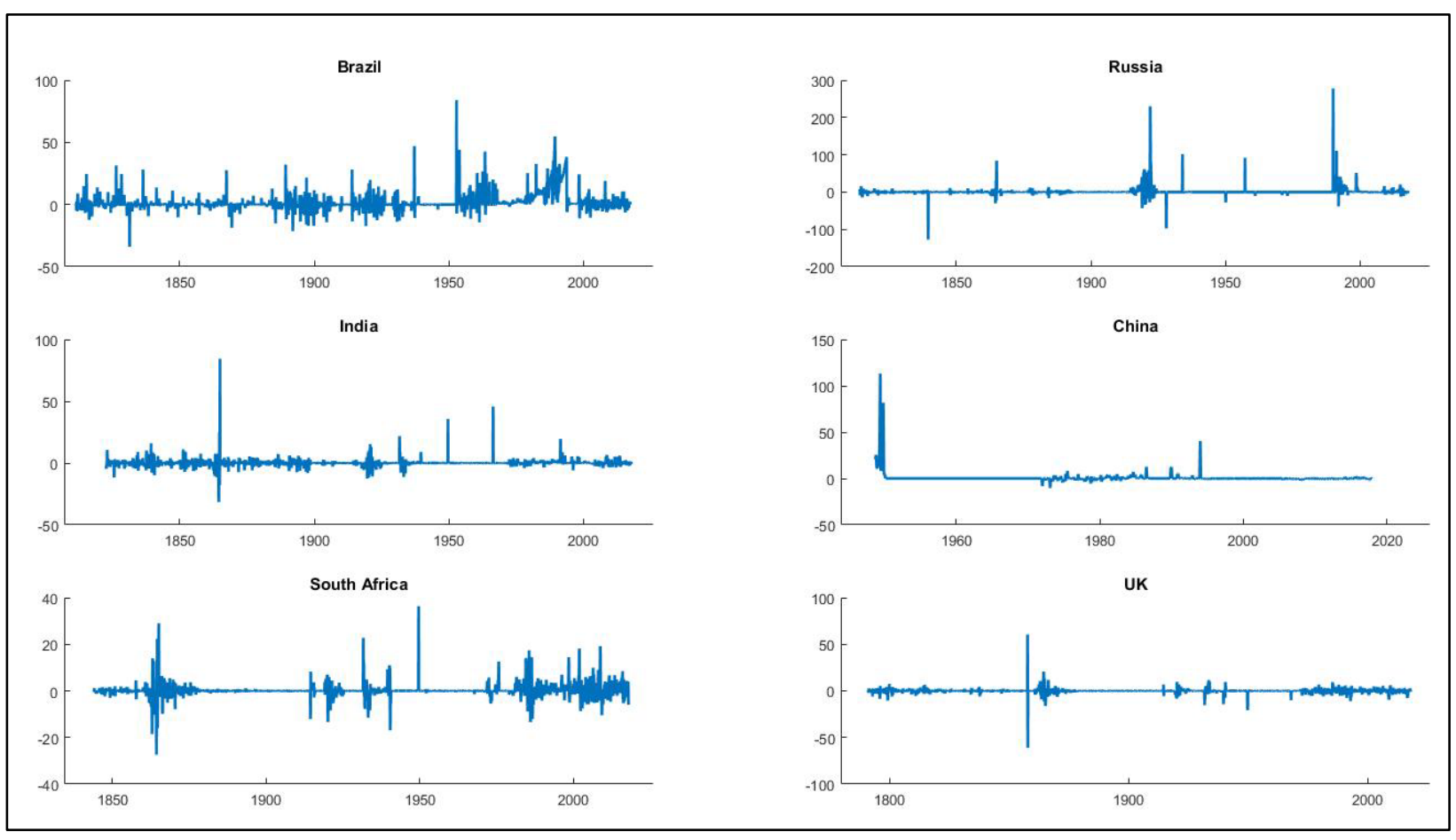

Following the suggestions of the reviewer we tet for the existence of nonlinearity and randomness in the data based on the BDS test and the correlation dimension, respectively. Aa a first step, we fit a GARCH $(1,1)$ model to each pair (in log returns to be consistent with the Lyapunov exponent) to remove the linear structure from the time series and keep any other strong leading indicator that creates nonlinearity behavior in the series. After taking the standardized residuals we apply the BDS test. The specific test evaluates the null hypothesis of i.i.d. in the residual time series. If we reject the null hypothesis then we can assume the existence of a deterministic (often 
chaotic) process that drives the series. In Table A2 we report the results from the BDS on the standardized residuals of a GARCH (1,1) model for each exchange rate.

\begin{tabular}{|c|c|c|c|c|c|}
\hline \multicolumn{7}{|c|}{ Table A2: BDS test results } \\
\hline Country/Dimension & $d=2$ & $d=3$ & $d=4$ & $d=5$ & $d=6$ \\
\hline Brazil & $0.05^{*}$ & $0.09^{*}$ & $0.12^{*}$ & $0.13^{*}$ & $0.13^{*}$ \\
\hline Russia & $0.07^{*}$ & $0.14^{*}$ & $0.18^{*}$ & $0.21^{*}$ & $0.23^{*}$ \\
\hline India & $0.02^{*}$ & $0.05^{*}$ & $0.07^{*}$ & $0.09^{*}$ & $0.10^{*}$ \\
\hline China & $0.08^{*}$ & $0.15^{*}$ & $0.21^{*}$ & $0.25^{*}$ & $0.27^{*}$ \\
\hline South Africa & $0.04^{*}$ & $0.08^{*}$ & $0.12^{*}$ & $0.15^{*}$ & $0.17^{*}$ \\
\hline U.K. & 0.00 & 0.00 & $0.02^{*}$ & $0.03^{*}$ & $0.04^{*}$ \\
\hline
\end{tabular}

Notes: * denotes rejection of the null hypothesis of i.i.d. residuals at the $1 \%$ level of significance.

As we observe, we reject the null hypothesis of i.i.d. for all BRICS exchange rates, suggesting the existence of nonlinearity in the log returns of the exchange rates. Nevertheles, while nonlinearity is an indication, it is not evidence of the existence of chaos. To measure the degree of complexity we calculate estimates of the correlation dimension (cd) over the range of embedding dimensions for up to $d=20$.

If the data are purely stochastic, the correlation dimension will equal the level of the embedding dimension, while if the data follow a deterministic process, the slope estimates will tend to zero after a dimension. In doing so we apply the algorithm of Grassberger and Procaccia (1983). The correlation dimension estimates are reported in Figure A2. Our results suggest that the correlation dimension estimates generally increase with embedding dimension but they are below the theoretical values for a completely random process nor they exhibit a significant reduction in the slope of the graph after a certain dimension. Thus, we cannot conclude to a certain result regarding the randomness of the data or the existence of a deterministic process as it is the case when we see chaos.

Figure A2: Correlation dimension 


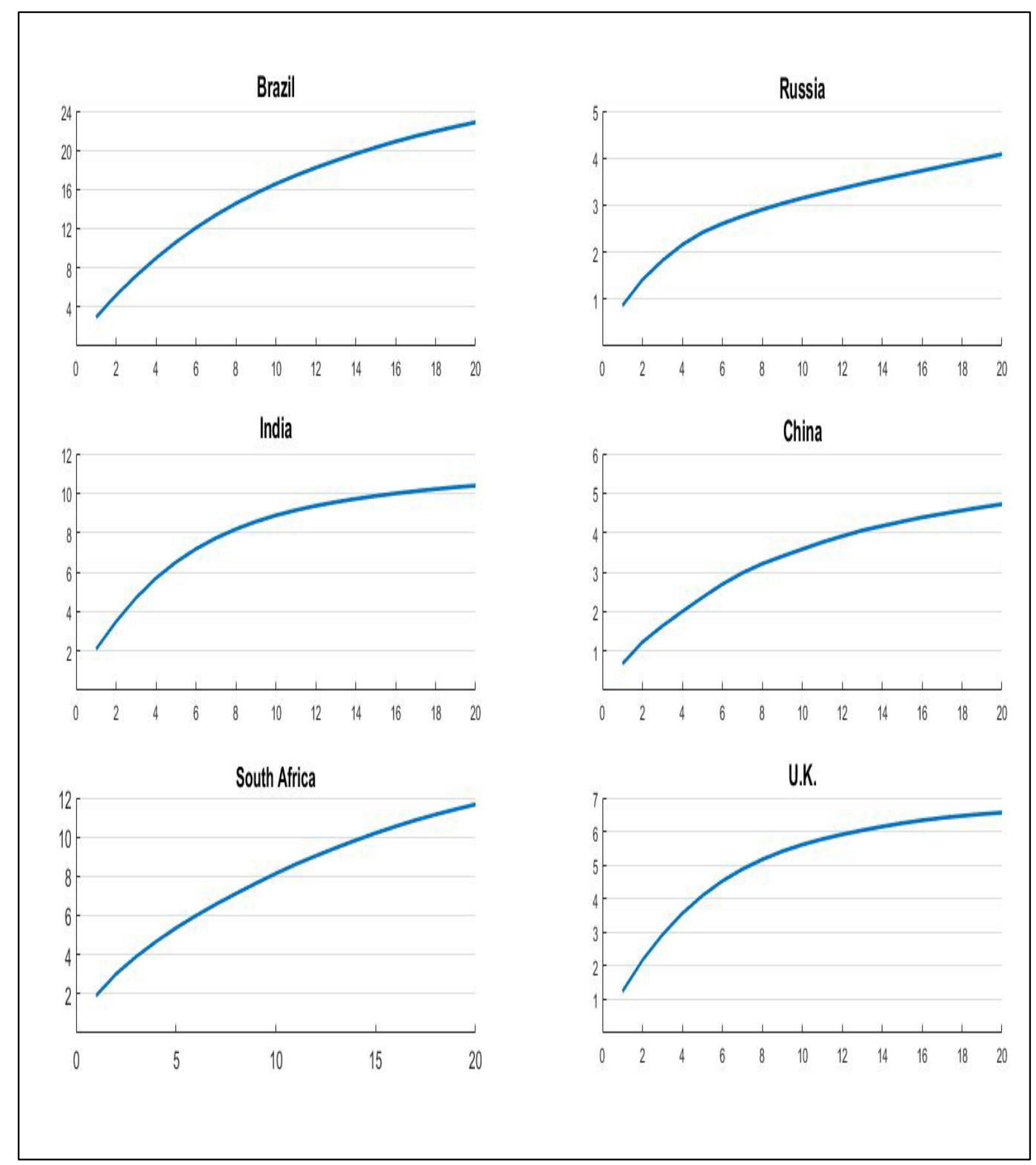




\section{References}

Grassberger P. and Procaccia I. (1983) Characterization of strange attractors. Physical Review Letters, 50(5), 346-349. 